\title{
DOCTRINA
}

\section{El impacto del covid-19 en las prisiones y la política penal en Alemania}

\author{
The impact of Covid-19 on prisons and penal policy in Germany
}

\author{
Frieder Dünkel \\ Universität Greifswald, Alemania
}

\begin{abstract}
RESUMEN En Alemania, la situación de las cárceles antes del estallido de la pandemia de covid-19 era bastante relajada, ya que la población carcelaria estaba en declive y el hacinamiento no era un problema. Sin embargo, existía un problema especial con los infractores de las multas, que representan alrededor del 10\% de la población penitenciaria adulta diaria en Alemania. Los reclusos de corta duración en general son un problema que resulta en una gran afluencia de personas posiblemente infectadas. Desde marzo de 2020, todos los estados federales alemanes dejaron de encarcelar (o redujeron) a los infractores de multas y algunos estados fueron más allá, al no ejecutar penas de prisión de hasta uno o incluso hasta tres años. La población carcelaria se redujo de unos 77 por cada 100.000 habitantes a 67. Sin embargo, las condiciones carcelarias empeoraron debido a los contactos restringidos de los presos con el mundo exterior. Por otro lado, se introdujo el acceso a la comunicación por internet para compensar el bloqueo de las visitas personales y de los permisos penitenciarios. Se analizan otras consideraciones de política criminal para abolir o reducir el incumplimiento de las multas y otros encarcelamientos de corta duración.
\end{abstract}

PALABRAS CLAVE Prisiones, covid-19, pandemia, alternativas al encarcelamiento, reforma penitenciaria.

ABSTRACT In Germany, the situation of prisons before the outbreak of the Covid-19 pandemic was quite relaxed as the prison population was in decline and overcrowding not a problem. However, there was a special problem with fine defaulters, who comprise about $10 \%$ of the daily adult German prison population. Short-term prisoners in general are a problem resulting in a large influx of possibly infected people. Since March 2020, all German Federal states stopped (or reduced) incarcerating fine defaulters and some states went further, not executing prison sentences of up to one or even up to three years. The prison population dropped from about 77 per 100,0oo inhabitants to 67 . Prison conditions, however, worsened because of restricted contacts of prisoners with 
the outside world. On the other side, access to internet communication was introduced to compensate the lockdown of personal visits and of prison leaves. Since June, some of the restrictions were repealed, as the pandemic was under control and almost no infections were observed for prisoners. Visits and prison leaves gradually are allowed again in a limited way. Further crime policy considerations to abolish or reduce fine default and other short-term imprisonment are discussed.

KEYWORDS Prisons, Covid-19, pandemic, alternatives to incarceration, prison reform.

\section{Introducción: La situación general en las cárceles alemanas}

Alemania ha operado como República Federal desde 1949. Tras la ruptura del muro y la transición de Alemania Oriental a una sociedad democrática en 1990, Alemania Occidental y Alemania Oriental se unificaron. Con pocas excepciones, el sistema jurídico de Alemania Occidental se hizo cargo de todo el país. La competencia legislativa en materia de derecho penal, derecho procesal penal y el derecho penitenciario correspondía a la Alemania federal central, no al nivel de los estados federales. ${ }^{2}$ En 2006, una reforma de la Constitución (Grundgesetz) cambió las competencias legislativas en materia de derecho penitenciario al nivel de los estados federales. Por lo tanto, entre 2007 y 2015, los dieciséis estados federales tuvieron que aprobar una legislación penitenciara sustantiva para la ejecución de penas de prisión para adultos, leyes de prisión de menores para jóvenes y adultos jóvenes de 14 a 25 años, leyes de prisión preventiva y leyes para la ejecución de prisión preventiva, una medida de seguridad indeterminada y de tratamiento para delincuentes peligrosos.

La política general de imposición de penas en Alemania es bastante moderada y estable. Incluso en una época de aumento de los delitos violentos durante la década de 1990 y principios de los 200o, hubo una distribución estable de sanciones: alrededor del $82 \%$ de las condenas contra adultos mayores de 18 años eran multas (según el llamado «sistema de multas diarias»), el 12\% eran sentencias suspendidas (libertad condicional) y el $6 \%$ penas de prisión. La duración media de las penas de prisión es de unos dos años. No hay evidencia de un giro punitivo en las sentencias, aunque las penas previstas legalmente por delitos violentos y sexuales aumentaron ligeramente (Dünkel: 2019).

En febrero de 2020, Alemania tenía una población carcelaria promedio de 63.852 reclusos, con 13.137 en prisión preventiva $(29,8 \%) .^{2} 45.062$ cumplían una pena de pri-

1. Véase para la evolución del sistema penitenciario alemán, Dünkel y Rössner (2001) y Dünkel (2018).

2. Los datos estadísticos sobre la población penitenciaria y la distribución de los reclusos en comparación con los estados federales se toman de Statistisches Bundesamt, «Rechtspflege. Bestand der Gefangenen und Verwahrten in den deutschen Justizvollzugsanstalten nach ihrer Unterbringung auf 


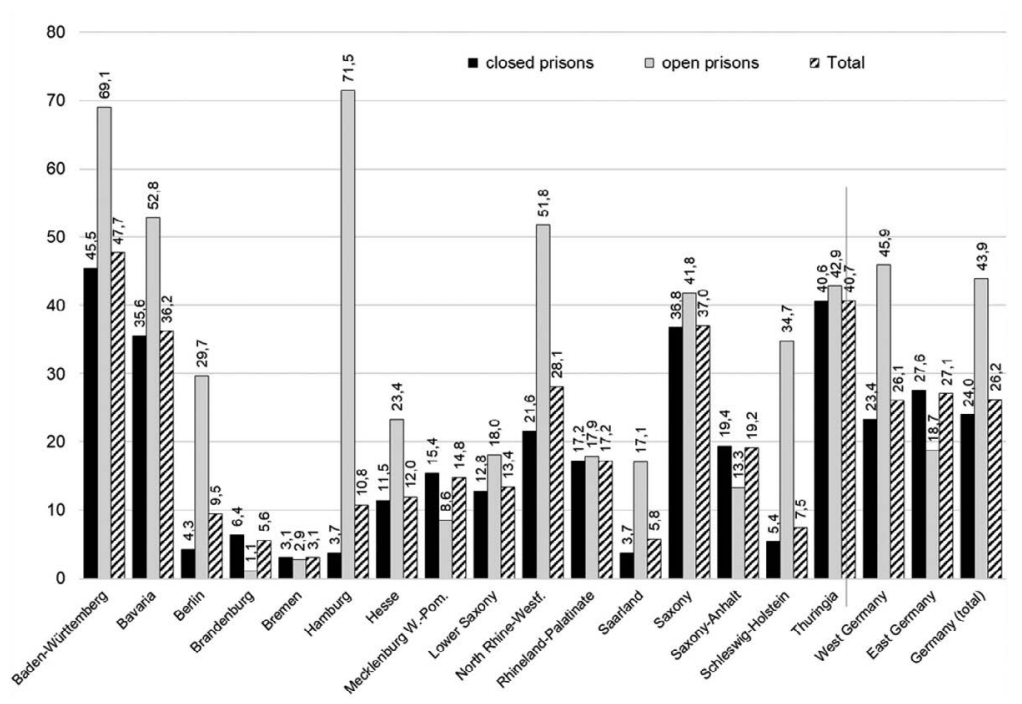

Figura 1. Porcentaje de presos en celdas comunales en cárceles cerradas y abiertas el 31 de marzo de 2019.

sión en las cárceles para adultos, de los cuales 4.773 (9,4\%) cumplían una pena de prisión sustitutiva por no haber pagado una multa (morosos).

A finales de febrero de 2020, 47.855 de los 63.851 prisioneros estaban alojados en celdas individuales (75\%), y 15.996 (25\%) en celdas comunales, en su mayoría solo con otro recluso (figura 1 ).

Según los datos recopilados por el Centro Internacional de Estudios Penitenciarios de Londres (Universidad de Birckbeck) ${ }^{3}$ para septiembre de 2019, Alemania tenía la misma población carcelaria de 63.851 reclusos que a fines de febrero de 2020, lo que representa una tasa de población carcelaria de 77 por cada 100.000 habitantes. La tasa de población carcelaria desde 2004 (96 cada por 100.000) ha disminuido cerca de $20 \%$ y se mantuvo estable desde $2013,{ }^{4}$ aunque se temía que la crisis de refugiados de 2015 contribuyera a un aumento de la población carcelaria. Los datos del informe mundial de prisiones de marzo de 2020 informaron una tasa de población carcelaria de 71. El número absoluto de presos disminuyó aún más a fines de junio, llegando a 55.525 , lo que significaría una tasa de población carcelaria de 67, que -en comparación internacional - es excepcionalmente baja (Dünkel: 2017).

Haftplätzen des geschlossenen und offenen Vollzugs» (estadísticas mensuales sobre reclusos en instalaciones penitenciarias cerradas y abiertas), disponibles en destatis.de.

3. Véase el informe sobre las prisiones del mundo: «Highest to lowest, prison population total», World Prison Brief, disponible en https://bit.ly/3qd81mP.

4. Véase, para la evolución alemana en comparación con otras jurisdicciones europeas, Dünkel (2017). 


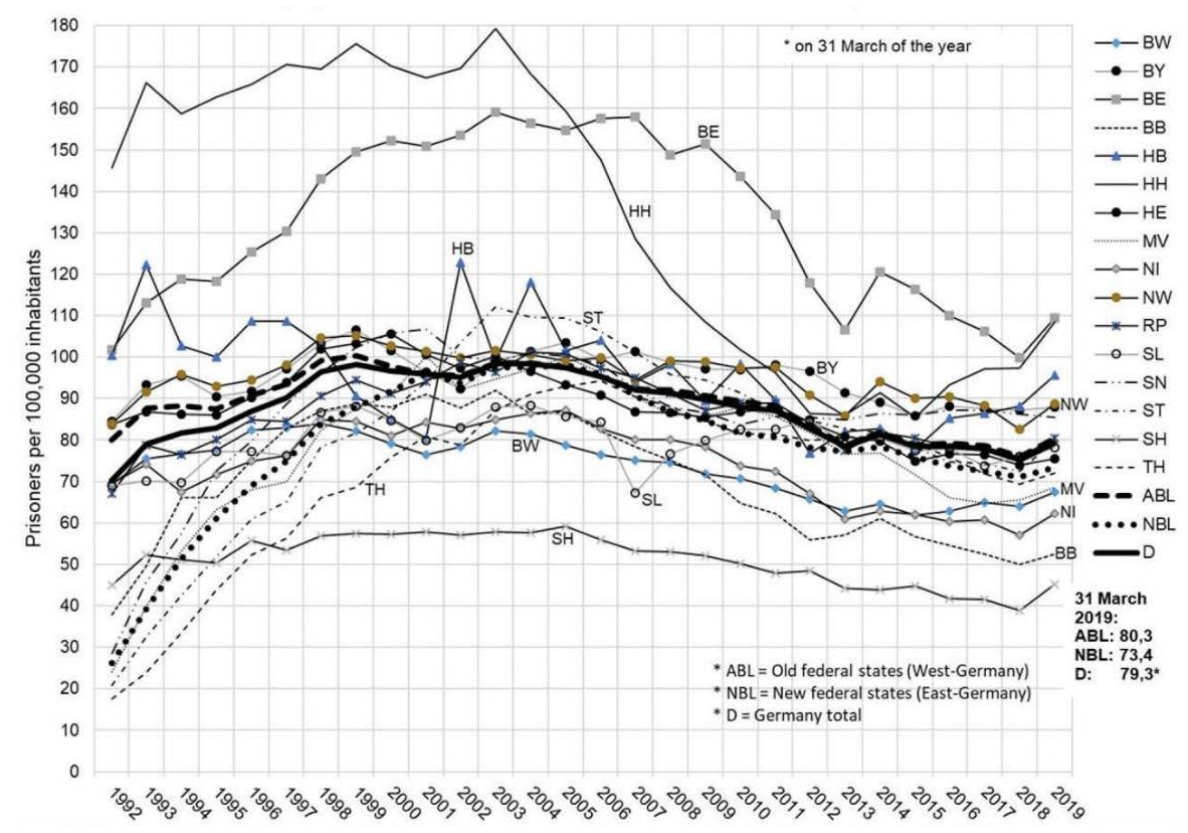

Figura 2. Tasas de población carcelaria en los estados federales alemanes, 1992-2019.

A pesar de las considerables disparidades regionales, la tendencia a la baja es más o menos uniforme para los dieciséis estados federales (figura 2). Se puede observar una caída en particular grande de la población carcelaria en los estados federales de Hamburgo (desde 2003) y Berlín (desde 2009), que antes tenían una población carcelaria considerablemente más alta que la media (véase Dünkel: 2018).

El nivel de ocupación a finales de febrero de 2020 era del $90 \%$, lo que significa que el hacinamiento (aparte de algunas cárceles cerradas) no era en general un problema en Alemania. La figura 3 revela que en 2019 la tasa de ocupación general con 90\% fue idéntica, mientras que solo en el estado federal de Baden-Württemberg superó el 100\%.

La situación se ha calmado aún más debido a la liberación y no ejecución de penas de prisión de corta duración desde marzo de 2020, con un nivel de ocupación de $83,3 \%$. A finales de junio de 2020 , la tasa de ocupación era solo del $76 \%$. Por lo tanto, en este momento, el hacinamiento -incluso en las regiones de alguna manera problemáticas antes del brote de la pandemia (ver figura 3) - no es un problema en toda Alemania.

Uno de los riesgos de infección se deriva de alojar a demasiados presos en alojamientos pequeños e higiénicamente problemáticos. En Alemania, los presos tienen, en principio, derecho a ser alojados en una sola celda por la noche. Este requisito legal no se cumple por completo en todos los estados federales y cárceles. A finales de febrero de 2020, el 75\% de los presos (preventivos y condenados) estaban alojados en celdas individuales (47.855 de 63.851) y el $25 \%$ en celdas comunales (un año antes, en 


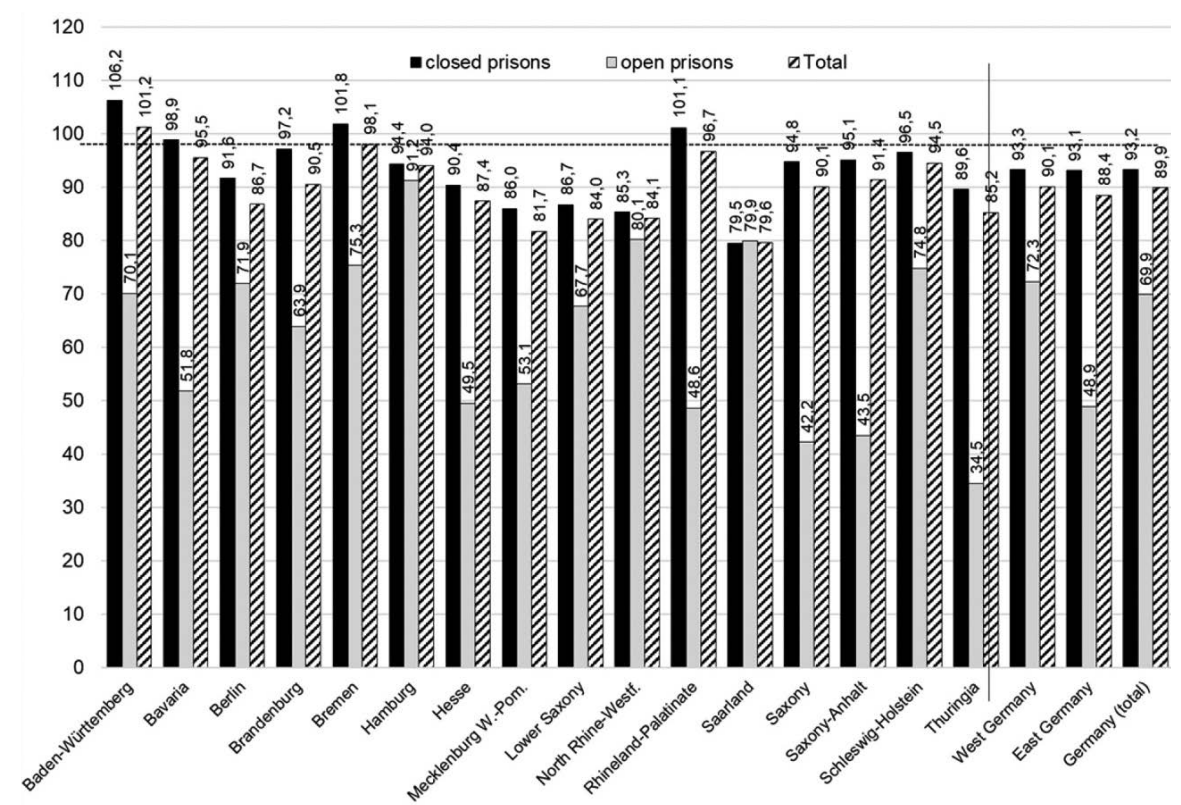

Figura 3. Tasa de ocupación en centros penitenciarios cerrados y en centros penitenciarios de régimen abierto (presos sentenciados y no juzgados por 100 plazas al 31 de marzo de 2019).

marzo de 2019: $64 \%$ en solitario, $26 \%$ en celdas comunales), nuevamente con grandes disparidades regionales (ver figura 1).

Un mes después, la población carcelaria había disminuido en 4.364 presos, lo que se debió a liberaciones o a la no ejecución de penas de prisión de corta duración debido a la pandemia de covid-19. La proporción de presos alojados en celdas individuales aumentó del 75\% al 77,5\% a finales de marzo de 2020 .

El sistema penitenciario alemán —así como el sistema de sanciones comunitarias- se basa en el objetivo de rehabilitación o el principio de reinserción social (Resozialisierung). Está consagrado en el derecho penal y penitenciario sustantivo y reconocido con respecto al sistema penitenciario por el Tribunal Constitucional Federal (FCC) como un principio constitucional basado en el derecho de los reclusos a preservar la dignidad humana (artículo 1 de la Constitución, Grundgesetz) y el principio del estado de bienestar social (artículo 20 de la Constitución) (véase Morgerstern, 2016; Pruin, 2019: 150 y ss.).

El principio de reintegración social requiere un mecanismo de relajación gradual del sistema penitenciario que incluya permisos penitenciarios regulares y el traslado a cárceles abiertas al menos en la última etapa de ejecución de las penas de prisión (Dünkel y Rossner, 2001: 327 y ss.; Dünkel, 2018: 428 y ss.). Como consecuencia de esta orientación a los programas de reingreso, cada día varios miles de presos conde- 
nados se encuentran en permisos temporales (a fines de febrero de 2020 eran 2.847 , es decir, el 5,6\% de la población de 50.675 presos condenados). La proporción de presos ausentes temporalmente se redujo a fines de marzo a $1.761 \mathrm{y}$ a fines de junio a 1.776, es decir, el 3,7\% y, en consecuencia, el $4 \%$ del total de presos condenados. ${ }^{5} \mathrm{El}$ impacto de la pandemia con la restricción de los permisos penitenciarios es bastante visible por estos datos estadísticos.

Otro pilar de la orientación a la reinserción social es el traslado a cárceles abiertas, que se definen como instalaciones sin obstáculos físicos para evitar la fuga (es decir, no hay muros ni ventanas enrejadas). El principio de una apertura gradual de las cárceles se basa en la confianza en los presos, quienes naturalmente son seleccionados en función de su peligrosidad y riesgo de fuga. ${ }^{6} \mathrm{~A}$ fines de febrero de 2020 , el $15 \%$ de los 45.062 presos que cumplían una pena de prisión en las cárceles para adultos se alojaron en una instalación abierta, frente al 8,8\% de los 3.557 reclusos de 14 a 24 años que cumplen una pena de prisión juvenil en cárceles juveniles. A finales de marzo de 2020, las proporciones eran aproximadamente las mismas: el 14,9\% de los 42.177 reclusos en las cárceles de adultos, frente al 8,6\% en las cárceles para jóvenes, estaban alojados en cárceles abiertas.7 Por lo tanto, las restricciones ordenadas por la administración penitenciaria no son visibles en lo que respecta al traslado a cárceles abiertas, pero se puede suponer que las restricciones relativas a los permisos penitenciarios que se concentran típicamente en los presos en instalaciones abiertas, durante el período principal de la pandemia también han influido la práctica en instalaciones abiertas.

\section{Sentencia y ejecución de sentencias y políticas antes y después de la pandemia e impacto en las tasas de población carcelaria}

Los siguientes hallazgos sobre los cambios en la ejecución de las penas de prisión y en las políticas penitenciarias con respecto a la crisis del coronavirus se basan en una investigación de Christine Morgenstern, del Departamento de Criminología en

5. El número absoluto de presos condenados era de 42.195 a finales de marzo y 45.715 a finales de junio de 2020.

6. Esto no significa que solo se conceda a los delincuentes de bajo riesgo el cumplimiento de su condena en prisiones abiertas. Asimismo, los infractores de riesgo medio y alto -al menos en las últimas etapas de ejecución de las penas de prisión- deberían tener derecho a ser trasladados a cárceles abiertas para aliviar el proceso de transición de las cárceles cerradas a un entorno abierto y situación de cuidados posteriores. Véase para ello Dünkel en Dünkel y otros (2016: 91 y ss.).

7. A fines de junio de 2020, la proporción de reclusos alojados en cárceles abiertas para adultos era del $14,1 \%$ y en cárceles para jóvenes del 8,2\%, lo que subraya la afirmación de que la pandemia no tuvo un impacto visible en la estrategia de promover el reingreso de los reclusos mediante una liberación gradual y el traslado a cárceles abiertas. Sin embargo, es necesario más análisis estadísticos sobre la cuestión de los efectos diferenciales y sobre qué grupos de delincuentes se seleccionaron preferentemente. 
Greifswald (también Trinity College, Dublín) en marzo y en otras investigaciones en junio y julio por el autor de este artículo.

Como se mencionó, Alemania es un estado federal con dieciséis estados (Länder), todos los cuales tienen leyes penitenciarias propias. Por lo tanto, tuvimos que explorar los enfoques - a veces- diferentes en la legislación y la práctica penitenciaria de los dieciséis estados federales. La práctica de dictar sentencia de los tribunales se basa en el (uniforme) Código Penal Federal. Las disparidades regionales en las prácticas de imposición de penas son bien conocidas. Durante la pandemia, los tribunales se vieron limitados en su trabajo y se ocuparon principalmente de los casos de presuntos delincuentes enviados a prisión preventiva. Por lo tanto, la afluencia de nuevos ingresos a las cárceles se redujo en parte debido al menor número de condenas entre marzo y junio de 2020. Aún no se dispone de cifras exactas, pero las estadísticas penitenciarias sobre ingresos dan alguna indicación de la dimensión: en febrero de 2020, 7.799 nuevos ingresos (Erstaufnahmen im Strafvollzug), mientras que en marzo de 2020 las estadísticas contaron solo 5.470, y en junio 4.216 ingresos en las cárceles (menos 45,9\%).

Una pregunta de investigación para las administraciones penitenciarias del estado federal fue si los presos eran liberados y qué formas de sentencias de prisión no se ejecutan debido al covid-19 para disminuir el riesgo de que los presos se infecten. Los resultados son unánimes en la medida en que todos los estados federales declararon haber dejado de ordenar a los condenados que cumplieran condenas por incumplimiento de multa y la mayoría de los estados liberaron a los presos que cumplían condenas por incumplimiento de multa por defecto al comienzo de la crisis en marzo de 2020. La reducción de la población penitenciaria diaria que cumple penas de prisión por el no pago de multas es claramente visible desde marzo de 2020. Las cifras absolutas de la población diaria por impago de multas se redujeron en $72 \%$ entre febrero y junio de 2020, la proporción con respecto a la población carcelaria de delincuentes adultos del 10,6\% al 5,8\% a finales de marzo (tabla 1) y más al 3,5\% en junio (menos $67 \%$ ).

Aunque todos los estados federales habían declarado que no se ejecutarían las sentencias de multa por incumplimiento, esta política se aplicó hasta finales de marzo de manera bastante reticente en Baviera, Baja Sajonia y Sajonia-Anhalt. En Renania del Norte-Westfalia la disminución también fue inferior a la media. Por el contrario, en Baden-Wurtemberg, Berlín, Hamburgo y Mecklemburgo-Pomerania Occidental, la población de morosos se redujo en $75 \%$ o más (tabla 2 ).

Con el fin de ciertas restricciones del encierro desde mayo de 2020 fuera de las cárceles, algunas administraciones penitenciarias comenzaron a ralentizar la no ejecución de las penas de multa por incumplimiento. Sin embargo, todos los estados federales mantuvieron su política de no ejecutar estas breves penas de prisión, en particular Berlín, Brandeburgo, y Mecklemburgo-Pomerania Occidental. Solo man- 
Tabla 1. Multas a los morosos en el sistema penitenciario de adultos en Alemania (cifras absolutas al final del mes)

\begin{tabular}{|c|c|c|c|}
\hline & $\begin{array}{l}\text { Prisioneros que cumplen una pena } \\
\text { de prisión en prisiones para adultos }\end{array}$ & Presos morosos & $\begin{array}{l}\text { Porcentaje de presos } \\
\text { en cárceles de adultos }\end{array}$ \\
\hline \multicolumn{4}{|l|}{2019} \\
\hline Marzo & 46.477 & 4.861 & $10,5 \%$ \\
\hline Abril & 45.917 & 4.546 & $9,9 \%$ \\
\hline Mayo & 46.008 & 4.549 & $9,9 \%$ \\
\hline Junio & 45.687 & 4.482 & $9,8 \%$ \\
\hline Septiembre & 45.244 & 4.616 & $10,2 \%$ \\
\hline Diciembre & 43.760 & 4.122 & $9,4 \%$ \\
\hline Promedio 2019 & $45.417,8$ & $4.569,5$ & $10,1 \%$ \\
\hline \multicolumn{4}{|l|}{2020} \\
\hline Enero & 44.720 & 4.664 & $10,4 \%$ \\
\hline Febrero & 45.062 & 4.773 & $10,6 \%$ \\
\hline Marzo & 42.177 & 2.447 & $5,8 \%$ \\
\hline Abril & 39.528 & 1.553 & $3,9 \%$ \\
\hline Mayo & 38.595 & 1.312 & $3,4 \%$ \\
\hline Junio & 38.154 & 1.333 & $3,5 \%$ \\
\hline Promedio 2020 & $41.372,7$ & $2.680,3$ & $6,3 \%$ \\
\hline
\end{tabular}

tuvieron en prisión a los infractores multados que, además, debían cumplir otra pena de prisión. Solo unos pocos estados federales no solo aplazaron la ejecución de las sentencias de multa, sino que también otorgaron una amnistía con respecto a las multas impuestas originalmente (por ejemplo, Berlín).

Algunos estados federales fueron incluso más allá de la no ejecución de sentencias por incumplimiento de multa al no ejecutar penas de prisión de hasta seis meses (Baden-Wurtemberg, Baviera), doce meses (Baja Sajonia, Renania del Norte-Westfalia) o incluso hasta tres años (Berlín, Hamburgo, Sajonia). ${ }^{8}$ Hamburgo no comenzó a

8. Renania del Norte-Westfalia, en respuesta a una investigación parlamentaria, declaró que los presos que cumplían una pena de multa o de prisión de hasta dieciocho meses que finalizaba entre el 20 de marzo y el 31 de julio de 2020 habían sido puestos en libertad mediante la interrupción de la ejecución de la pena de acuerdo con el $\$ 455$ a de la Ley de Procedimiento Penal (por razones de organización). En total, 1.051 presos fueron puestos en libertad, lo que corresponde al 9,7\% de la población carcelaria de Renania del Norte-Westfalia en marzo de 2020, véase el impreso del Parlamento, Landtags-Drucksache 17/3468, del 8 de junio de 2020 . 
Tabla 2. Morosos en las cárceles alemanas para adultos antes y durante la pandemia de covid-19 en comparación con los estados federales (cifras definitivas al final del mes)

\begin{tabular}{|c|c|c|c|c|c|c|c|c|}
\hline Estado federal & $31 / 10 / 2019$ & $28 / 2 / 2020$ & $31 / 3 / 2020$ & $30 / 4 / 2020$ & $31 / 5 / 2020$ & $30 / 6 / 2020$ & $\begin{array}{c}\text { Cambio } \\
\text { febrero-marzo } \\
\text { de } 2020^{*}\end{array}$ & $\begin{array}{c}\text { Cambio } \\
\text { febrero-junic } \\
\text { de } 2020^{*}\end{array}$ \\
\hline Baden-Wurtemberg & 564 & 543 & 128 & 88 & 82 & 125 & 23,6 & 23 \\
\hline Baviera & 667 & 650 & 555 & 350 & 268 & 248 & 85,4 & 38,2 \\
\hline Berlín & 271 & 325 & 87 & 37 & 29 & 29 & 26,8 & 8,9 \\
\hline Brandeburgo & 156 & 175 & 22 & 15 & 14 & 23 & 12,6 & 13,1 \\
\hline Bremen & 47 & 53 & 28 & 14 & 13 & 13 & 52,8 & 24,5 \\
\hline Hamburgo & 116 & 118 & 29 & 16 & 19 & 43 & 24,6 & 36,4 \\
\hline Hesse & 388 & 391 & 166 & 94 & 92 & 92 & 42,5 & 23,5 \\
\hline $\begin{array}{l}\text { Mecklemburgo- } \\
\text { Pomerania Occidental }\end{array}$ & 105 & 78 & 17 & 14 & 8 & 13 & 21,8 & 16,7 \\
\hline Baja Sajonia & 346 & 358 & 289 & 178 & 135 & 125 & 80,7 & 34,9 \\
\hline $\begin{array}{l}\text { Renania del Norte- } \\
\text { Westfalia }\end{array}$ & 1.092 & 1.089 & 688 & 472 & 394 & 378 & 63,2 & 34,6 \\
\hline Renania-Palatinado & 192 & 206 & 91 & 67 & 63 & 44 & 44,2 & 21,4 \\
\hline Sarre & 34 & 35 & 19 & 12 & 8 & 13 & 54,3 & 37,1 \\
\hline Sajonia & 279 & 336 & 105 & 54 & 58 & 71 & 31,3 & 21,1 \\
\hline Sajonia-Anhalt & 168 & 205 & 154 & 101 & 78 & 60 & 75,1 & 29,3 \\
\hline Schleswig-Holstein & 90 & 78 & 24 & 11 & 18 & 19 & 30,8 & 24,4 \\
\hline Turingia & 123 & 133 & 45 & 30 & 33 & 37 & 33,8 & 27,8 \\
\hline Alemania (total) & 4.598 & 4.773 & 2.447 & 1.553 & 1.312 & 1.333 & 51,3 & 29 \\
\hline
\end{tabular}

* Índice $2 / 2020=100$.

ejecutar penas de prisión de hasta tres años e interrumpió la ejecución de penas de hasta dieciocho meses. En algunos estados federales no está clara una decisión política decisiva, pero al parecer, algunos estados decidieron no liberar a otros prisioneros de corta duración que no fueran los infractores de multas. Los diferentes niveles de ocupación y los problemas de hacinamiento no pueden explicar las diferencias entre, por ejemplo, Berlín y Baviera, sino un clima más o menos punitivo en la política penal y penitenciaria, que tradicionalmente es más severo en Baviera y más relajado en Berlín.

La administración penitenciaria no tiene mucha influencia en una liberación anticipada después de la mitad o dos tercios de la pena de prisión (es una decisión del Tribunal de Ejecución de Penas, véanse los $\$ 55$, 57a Código Penal, 88, 89 de la Ley de 
Justicia Juvenil). ${ }^{9}$ No está claro si las declaraciones de la administración penitenciaria sobre la decisión de una liberación anticipada han cambiado a favor de otorgar más liberaciones de este tipo durante marzo y los meses siguientes en 2020. El número absoluto de liberaciones después de haber cumplido dos tercios de la pena de prisión entre enero y marzo de 2020 aumentó de 421 a $498,{ }^{10}$ pero también se pudo observar un aumento similar en el mismo período de 2019. Por lo tanto, no hay evidencia estadística que indique alguna relación causal, al menos no todavía.

\section{Medidas de la administración penitenciaria para proteger a los reclusos de la infección}

En marzo de 2020, las dieciséis administraciones penitenciarias de los estados federales tomaron medidas inmediatas para la protección de los reclusos y del personal de las prisiones. Al principio, hubo escasez de mascarillas y materiales de higiene, pero a mediados de abril se resolvió este problema. Debido a la reducción del número de presos y de ingresos a las cárceles, todos los centros penitenciarios dispusieron de capacidad para establecer zonas de cuarentena y para alojar a nuevos presos en estas áreas durante cerca de dos semanas.

Ya hemos tratado otras medidas destinadas a reducir la afluencia de nuevos presos mediante la no ejecución de penas de prisión de corta duración. ${ }^{11}$

\section{Infecciones por covid-19 en las cárceles}

Desde marzo hasta finales de julio, solo unos pocos presos y miembros del personal se vio infectado. Los prisioneros infectados fueron separados de inmediato, puestos en cuarentena y ningún prisionero murió debido o en combinación con covid-19. Aunque faltan datos completos para todos los estados federales, el más grande, Renania del Norte-Westfalia, informó el 16 de julio de 2020 que 11 prisioneros habían sido infectados y todos se han recuperado. Con respecto a una población penitenciaria total de 15.307 en marzo de 2020, esto significa un porcentaje del o,07\%. Según los datos disponibles, la mayoría de los demás estados federales han registrado menos de 10 infecciones de prisioneros y, por lo tanto, prácticamente no se vieron afectados por la

9. Véase, para los requisitos legales en Alemania y en comparación con otras jurisdicciones europeas, Dünkel (2015) y Dünkel y Weber (2019).

10. Las cifras absolutas se mantuvieron en este nivel relativamente alto también en los meses de abril a junio de 2020 (498, 506 y 471), dejando abierta la cuestión de una política de liberación anticipada más favorable inducida por la pandemia.

11. Lamentablemente, Alemania no informa de las medidas adoptadas contra las infecciones por covid-19 y otros cambios en la vida penitenciaria durante la pandemia a la plataforma de internet Europris, aunque el Ministerio Federal de Justicia es miembro. Véase europris.org. 
pandemia. En Baviera, 13 presos y 28 miembros del personal se infectaron a mediados de mayo (la población penitenciaria promedio en marzo de 2020 era 11.416), es decir, la tasa de infección fue de aproximadamente el o,1\%, en Berlín solo dos presos y en el pequeño estado de Sarre ninguno.

La política general es no aislar a todo el grupo de reclusos, sino solo a los que dan positivo a la prueba del virus.

En cuanto a las infecciones de los funcionarios penitenciarios, de nuevo Renania del Norte-Westfalia informó que 35 miembros del personal estaban infectados desde el brote de covid-19, de los cuales 32 se han recuperado.

En general, se puede decir que las administraciones penitenciarias alemanas tuvieron mucho éxito en mantener el covid-19 fuera de las prisiones.

\section{Contactos con el mundo exterior para los prisioneros durante la pandemia}

Todos los estados federales han restringido las visitas suspendiendo las con contacto personal. Algunas cárceles disponen de instalaciones para visitantes con ruedas de corte (Trennscheibe), donde los presos pueden ver a sus visitantes, pero están separados por una ventana de plexiglás. Algunas cárceles han introducido este tipo de instalaciones. No están restringidas las visitas de abogados, en particular en prisión preventiva, pero si es posible también se ejecutan con ruedas de corte.

La mayoría de los estados federales ha introducido algunas medidas compensatorias, como videollamadas (Skype y otras), pero no está claro si la compensación es algo más que simbólica para algunos casos. Un ejemplo muy positivo es que, ya antes de la aparición de la pandemia, el estado de Baja Sajonia había introducido teléfonos móviles individuales en cada una de las celdas de los prisioneros, lo que les permite tener llamadas telefónicas todos los días con sus familiares y amigos. En las cárceles abiertas, a los presos se les permitía y ahora pueden usar teléfonos móviles. La cantidad de visitas regulares es de 2 a 4 horas al mes y visitas adicionales para familiares y niños.

En las cárceles cerradas se han suspendido los permisos penitenciarios (permisos diurnos de varias horas y permisos prolongados de varios días). También en los regímenes penitenciarios abiertos se han introducido restricciones similares, por un lado, pero también se conceden permisos de larga duración de dos semanas o más (en algunas jurisdicciones estatales son posibles los permisos de larga duración de hasta seis meses), pero probablemente esto solo concierne algunos casos individuales. El bloqueo de la concesión de permisos penitenciarios y de los planes de salida laboral en las cárceles cerradas impacta en forma negativa los esfuerzos de preparación de la salida y de una gestión sistemática de transición. Uno de los factores clave de la reinserción social en el sistema penitenciario alemán es la preparación temprana para la liberación y los contactos entre la prisión y los servicios de asistencia posterior, 
que tienen como objetivo un sistema de atención integral similar al establecido en varios estados federales, como Mecklemburgo-Pomerania Occidental o Renania del Norte-Westfalia (véase Pruin, 2019; Dünkel y Weber, 2019). Esto subraya la necesidad de continuar con las consideraciones de política criminal (reductionist) establecidas al final del documento para minimizar los impactos negativos de la crisis de coronavirus en las cárceles.

Desde junio, los presos en Renania del Norte-Westfalia pueden recibir visitas de un familiar y, además, de sus hijos. Regulaciones similares y la relajación de las medidas de encierro son visibles también en los demás estados federales. Sin embargo, la mencionada ventana de plexiglás está siendo la forma habitual para las visitas.

\section{El impacto del covid-19 en la vida cotidiana en prisión: Actividades (trabajo, programas de reingreso, deportes, etcétera)}

Otras actividades comunes (trabajo, actividades recreativas) se han reducido en forma parcial. En caso de que se cerraran las instalaciones de trabajo, los reclusos, en consecuencia, no recibirían remuneración laboral. En lugar de unos ingresos de entre EUR 200 y 300, solo recibieron una paga de bolsillo de unos EUR 40. Sin embargo, algunos estados federales aumentaron la paga hasta el 70\% de la remuneración normal (por ejemplo, Baja Sajonia). En particular, en la prisión preventiva, la situación es difícil y puede significar que los presos permanezcan encerrados hasta 23 horas al día en sus celdas. En las cárceles para condenados también se ha reducido el tiempo de las actividades conjuntas con los compañeros de prisión, en particular, las actividades deportivas de equipo, como el fútbol. En cambio, se han ampliado otras actividades deportivas (trote, actividades en grupos reducidos, etcétera). Las administraciones penitenciarias tratan de encontrar un equilibrio entre las restricciones necesarias y calmar el enfado de los prisioneros con ellas ofreciendo actividades compensatorias.

Con respecto a las tasas de infección muy bajas, las actividades laborales desde junio y julio se están llevando a cabo de forma regular teniendo en cuenta las medidas de protección de coronavirus, como el uso de mascarillas y el distanciamiento.

\section{El lado positivo de la crisis pandémica: ¿Qué se podría reservar para seguir desarrollando las condiciones carcelarias y la situación laboral de los miembros del personal?}

La pandemia no solo tuvo un impacto negativo en los regímenes penitenciarios y la vida cotidiana en prisión. Algunas de las nuevas formas de comunicación a través de internet (Skype y otros) han demostrado ser manejables sin mayores problemas de seguridad. Estas formas de comunicación también se han utilizado para audiencias judiciales (sobre la prisión preventiva o libertad anticipada). Las experiencias con 
estas formas de comunicación deberían aprovecharse también en el futuro. Permitir a los presos la comunicación por Skype o similar está en consonancia con el objetivo de proteger la vida familiar e intensificar las relaciones con la pareja, los hijos y los amigos.

En cuanto a las condiciones de trabajo de los funcionarios, otra buena experiencia fue la de permitir el trabajo en casa, al menos para algunos trabajos administrativos, naturalmente no tareas de supervisión.

La pandemia ha provocado la interrupción de la ejecución de penas de prisión de corta duración, lo cual — debido a sus efectos perjudiciales para la reinserción social (Dünkel, 2020) y su impacto negativo en la gestión penitenciaria (con un elevado número de reclusos entrantes y salientes) - es un hecho principalmente deseable. Sin embargo, no debemos limitarnos a reinstalar la misma situación que teníamos antes de la pandemia una vez que haya cesado el encierro, sino que debemos pensar en crear posibilidades para sustituir el encarcelamiento de corta duración por modos alternativos de ejecutar las penas de prisión. En países como Finlandia, Austria, Inglaterra, Escocia, Gales, Lituania, los Países Bajos, España o Suiza, las penas cortas de prisión o un breve remanente de las penas de larga duración pueden cumplirse bajo supervisión probatoria, llevando a cabo trabajos de servicio comunitario en la comunidad o cumpliendo un período específico bajo arresto domiciliario electrónico (véase Dünkel y Weber, 2019: 408 y ss.). En Finlandia - y en la mayoría de los países mencionados-, con condenas de hasta seis meses, hay un adelanto de facto de la libertad (anticipada). La decisión la toma la administración de la prisión, es decir, su director. La introducción de formas alternativas de ejecutar penas de prisión breves puede reducir en forma considerable la población carcelaria. Realmente reemplaza el encarcelamiento y no otras sanciones alternativas (abordando el problema de la ampliación de la red).

Por el momento, una amnistía para los delincuentes cuya ejecución de una pena de prisión de corta duración fue interrumpida sería una solución factible (un ejemplo positivo en la práctica es la ya mencionado en Berlín; véase también Feest, 2020: 120-121; en Renania del Norte-Westfalia, condenas de un máximo de poco más de cuatro meses), ya que es una carga particularmente alta cumplir una pena de prisión corta, tal vez después de un año, cuando el infractor ha demostrado su integración social en el trabajo y la vida familiar.

\section{Cambios en las leyes penales y penitenciarias y perspectivas para una política penal reduccionista}

El debate en Alemania va en dos direcciones: ¿necesitamos reformas en el derecho penal y penitenciario, por ejemplo, para penalizar el incumplimiento de las restricciones inducidas por la pandemia? ¿Deben las leyes penitenciarias suavizar las res- 
tricciones practicadas durante la pandemia? Por otro lado, se plantea un debate contra la política de encarcelamiento hacia las penas de corta duración.

En cuanto al derecho penal general (Strafgesetzbuch, StGB), no se prevén cambios relacionados con la crisis del coronavirus. El incumplimiento de las restricciones de contacto no es un delito punible (tampoco hay demanda por ello), pero puede dar lugar a una multa administrativa y la cuantía de estas multas se han incrementado en los últimos días (agosto de 2020) luego de algunos eventos colectivos con personas que no llevaban mascarillas o celebraban fiestas sin mantener suficiente distancia. Estas multas nunca pueden terminar en penas de prisión sustitutivas.

En cuanto a las leyes penitenciarias, no se discuten cambios en ese nivel, pero todas las restricciones se basan en la legislación penitenciaria vigente y en las directrices de la administración penitenciaria. Sin embargo, se está iniciando un debate sobre hasta qué punto estas restricciones son justificables y es probable que las decisiones de los tribunales se den a conocer en un futuro próximo. Las restricciones de las visitas y otros contactos con el mundo exterior pueden infringir el derecho penitenciario sustantivo y también derechos humanos constitucionales de los presos y sus familias. Las administraciones penitenciarias han reaccionado recientemente a estos debates reduciendo las restricciones y ampliando las flexibilizaciones de los regímenes penitenciarios.

La pregunta general de la política criminal planteada (principalmente) por los académicos es: ¿no deberíamos utilizar la pandemia como un recordatorio de que encarcelamos a personas que no deberían estar en prisión y que, por el contrario, podrían ser sancionadas en la comunidad? En Alemania, el gran número de morosos por multas es sin duda un problema y la presión de los partidos políticos verdes y de izquierda aumenta. Al igual que en otros países europeos, el encarcelamiento por no pago de multas podría evitarse en gran medida mediante formas alternativas de ejecución de las multas y su sustitución por servicios comunitarios o la supresión total del encarcelamiento por no pago de multas mediante la transferencia de la ejecución a organismos de derecho civil (Dünkel, 2019).

Muchos académicos aprovechan también la oportunidad para recordar la despenalización de las drogas blandas y de la posesión para el consumo de todas las drogas, así como los delitos menores contra la propiedad, que para los reincidentes pueden dar lugar a penas de prisión (Dünkel, 2019, 2020; Harrendorf, 2020; Mohr, 2020). Alemania tiene la mayor proporción de reclusos de corta duración en Europa (Dünkel, 2017: 642-643), principalmente por el problema de la morosidad de las multas, pero también por las numerosas penas de prisión de corta duración (aunque una reforma de la ley en 1969 quería prohibirlas, véase Dünkel, 2019). Por lo tanto, es evidente la necesidad de nuevas reformas del derecho penal y del sistema de sanciones penales (Mohr, 2020). 


\section{Reconocimiento}

Artículo originalmente publicado en inglés como «The impact of Covid-19 on prisons and penal policy in Germany» en Victims \& Offenders, volumen 15, números 7-8 (2020), pp. 1.113-1.123, DOI: 10.1080/15564886.2020.1813230. Traducción de Gaspar Muchenik Ruiz, egresado de Derecho de la Universidad de Chile y ayudante ad honorem del Departamento de Ciencias Penales.

\section{Referencias}

DüNKel, Frieder (2015). «Mandatory release versus discretionary release: A comparative approach». En Martine Herzog-Evans (editor), Offender-release and supervision: The role of courts and the use of discretion (pp. 167-192). Nijmegen: Wolf Legal Publishers.

-. (2017). «European penology: The rise and fall of prison population rates in Europe in times of migrant crises and terrorism». European Journal of Criminology, 14 (6): 629-653. DOI: $10.1177 / 1477370817733961$.

-. (2018). «Strafvollzug». En Dieter Hermann y Andreas Pöge (editores), Kriminalsoziologie: Handbuch für Wissenschaft und Praxis (pp. 399-438). Baden-Baden: Nomos.

-. (2019). «Reforms of the criminal sanctions system in Germany: Achievements and unresolved problems». Juridica International, 28: 37-48. DOI: $10.12697 /$ JI.2019.28.05.

-. (2020). «Short-term imprisonment and the "reductionist" approach». En K. Beyens (editor), Liber amicorum for Sonja Snacken. Free University of Brussels. Artículo en preparación.

DüNKel, Frieder, Jörg Jesse, Ineke Pruin y Moritz von der Wense (editores) (2016). European treatment, transition management, and re-integration of high-risk offenders. Mönchengladbach: Forum Verlag Godesberg.

DüNKEL, Frieder y Dieter Rössner (2001). «Germany». En Dirk van Zyl Smit y Frieder Dünkel (editores), Imprisonment today and tomorrow: International perspectives on prisoners' rights and prison conditions (pp. 288-350). Segunda edición. Kluwer.

DüNKEL, Frieder y Jonas Weber (2019). "(Early) release, probation and collateral consequences (directives) after release: Legal conditions and practice». En Frieder Dünkel, Ineke Pruin, Anette Storgaard y Jonas Weber (editores), Prisoner resettlement in Europe (pp. 403-434). Routledge.

FeEsT, Johannes (2020). «Corona und Knast: Ein Zwischenbericht». Neue Kriminalpolitik, 32 (2): 113-122. DOI: 10.5771/0934-9200-2020-2-113.

HARRENDORF, Stefan (2020). «Plädoyer für eine umfassende Entkriminalisierung des Umgangs mit Betäubungsmitteln zum Eigenkonsum». En Kirstin Drenkhahn, 
Bernd Geng, Joanna Grzywa-Holten, Stefan Harrendorf, Christine Morgenstern e Ineke Pruin (editores), Kriminologie und Kriminalpolitik im Dienste der Menschenwürde: Festschrift für Frieder Dünkel zum 7o. Geburtstag (pp. 351-379). Forum Verlag Godesberg.

MoHr, Nicholas (2020). Die Entwicklung des Sanktionenrechts im deutschen Strafrecht: Bestandsaufnahme und Reformvorschläge. Mönchengladbach: Forum Verlag Godesberg.

Morgenstern, Christine (2016). «"Der Resozialisierungsgrundsatz”: Social reintegration as the dominant narrative for community punishment in Germany?» En Gwen Robinson y Fergus McNeill (editores), Community Punishment. European Perspectives (pp. 72-94). Routledge.

Pruin, Ineke (2019). «Prisoner resettlement in Germany». En Frieder Dünkel, Ineke Pruin, Anette Storgaard y Jonas Weber (editores), Prisoner Resettlement in Europe (pp. 150-166). Routledge.

\section{Sobre el autor}

Frieder DünKel es profesor y director del Centro de Derecho Penal y Criminología de la Universidad Ernst-Moritz-Arndt-Greifswald, Alemania. Ha sido investigador del Max Planck Institute of Foreign and International Criminal Law y presidente de la Sociedad Europea de Criminología (ESC), 2015-2016. Su correo electrónico es duenkel@uni-greifswald.de. 
La Revista de Estudios de la Justicia es publicada, desde 2002, dos veces al año por el Centro de Estudios de la Justicia de la Facultad de Derecho de la Universidad de Chile. Su propósito es contribuir a enriquecer el debate jurídico en el plano teórico y empírico, poniendo a disposición de la comunidad científica el trabajo desarrollado tanto por los académicos de nuestra Facultad como de otras casas de estudio nacionales y extranjeras.

\author{
DIRECTOR \\ Álvaro Castro \\ (acastro@derecho.uchile.cl) \\ SITIO WEB \\ rej.uchile.cl \\ CORREO ELECTRÓNICO \\ cej@derecho.uchile.cl \\ LICENCIA DE ESTE ARTÍCULO \\ Creative Commons Atribución Compartir Igual 4.o Internacional
}

La edición de textos, el diseño editorial y la conversión a formatos electrónicos de este artículo estuvieron a cargo de Tipográfica

(www.tipografica.io) 